\title{
Identifying Significant Changes in Serials with Title Changes in the Recognition of New Works
}

\section{Mavis B. Molto}

Due to an error during production of vol. 57, no. 3, appendixes were inadvertently omitted from this paper. Since the appendixes are intended to be read in conjunction with this paper, a decision was made to reissue "Identifying Significant Changes in Serials with Title Changes in the Recognition of New Works" in vol. 57, no. 4.-Ed.

The purpose of the study was to develop a means for identifying significant subject and function changes in serials with title changes and then to recommend ways to recognize new serial works in cataloging. A sample of serials with title changes was used to classify the underlying subject and function changes found into thirty-five subcategories, which were then each assigned a level (high, medium, or low) according to the evidence provided for a new work. The FRBR (Functional Requirements for Bibliographic Records) concept of a work and other FRBR guidelines were used in assigning the levels. It was determined that three high-level subject changes and one high-level function change provided the best evidence of significant change in recognizing a new work. Tests were performed to determine whether multiple medium-level changes could also be used to identify new works. A recommendation was made to modify the RDA (Resource Description and Access) rules for major change in the title proper of a serial to require a new access point only when a significant subject or function change has occurred in one of the four high-level subcategories identified in the study.

dilemma for serials catalogers over the years has been the issue of how to A treat title changes. When the Anglo-American Cataloguing Rules (AACR2) were revised in 2002, the initial goal was to provide rules requiring new records for serials with title changes only if the serial had become a new work. ${ }^{1}$ However, the mechanisms developed to recognize new works fell short of this objective. With the new Resource Description and Access (RDA) cataloging rules now

Mavis B. Molto (mavis.molto@usu.edu) is Serials Cataloger, Utah State University, Logan, Utah.

Submitted November 2, 2012; tentatively accepted pending modest revisions December 5, 2012; revision submitted December 29, 2012, and accepted for publication. replacing AACR2 in many libraries, the problem continues, since RDA employs many of the same procedures as AACR2. There is renewed emphasis in RDA, however, on the concept of a work because the rules are based on the FRBR (Functional Requirements for Bibliographic Records) conceptual model in which a work plays a prominent role. The work is one of four key entities that represent different aspects of a user's interest in bibliographic data. ${ }^{2}$ A work in RDA is defined, as in FRBR, as "a distinct intellectual or artistic creation."3 
In AACR2, new works are recognized by creating new entries for the manifestations of the new works, ${ }^{4}$ whereas RDA represents new works by new access points, along with entries for the new manifestations. ${ }^{5}$ The mechanism for recognizing new works in both AACR2 and RDA consists of determining that a major change has occurred, such as certain changes in the words of the title. The major changes that are identified, however, do not correlate with the changes that would be recognized if using a definition of a work that explains what a work is and how it can be recognized. Thus there is no assurance that the new entry or access point will represent a new work.

In a previous study, the author developed a preliminary procedure for recognizing new works for serials with title changes, using the FRBR definition of a work and additional FRBR guidelines. ${ }^{6}$ The study found that only two kinds of changes, namely, subject changes and function changes, provide the evidence needed to recognize a new work. The FRBR requirement that a significant change must occur was not addressed, this being beyond the scope of the study.

There is a need to address the issue of significant change in serials with title changes. The current study, a follow-up to the study noted above, will consider this problem and attempt to develop a means by which significant subject and function changes can be identified. Knowing how to discern significant changes in serials will provide a tool that could improve cataloging rules for serials. No study was found that addressed this issue.

The purpose of the study was to develop a means for identifying significant subject and function changes in serials with title changes and to recommend changes in cataloging rules for recognizing new serial works. The study was limited to serials that had title changes and did not address other kinds of changes in serials (e.g., changes in responsibility) that might also lead to the recognition of a new work. The study is expected to contribute to the theoretical body of knowledge concerning serials with title changes. It also will have a practical application in providing data that can be used to improve cataloging rules, specifically the RDA rules.

\section{Literature Review}

The literature review was concerned with three areas relating to the proposed research: (1) how to define a serial work, (2) how cataloging rules determine when a new record or access point should be created for a serial with a title change, and (3) the characteristics of serials with title changes.

\section{Concept of a Work in the Library Catalog}

There are various views on how to define a work for the library catalog, as well as differences in how cataloging rules treat this issue. AACR2 does not provide a definition of a work, whereas in RDA the FRBR definition is used. The FRBR conceptual model, on which RDA is based, was developed by a study group of the International Federation of Library Associations and Institutions (IFLA) which published a report titled Functional Requirements for Bibliographic Records. The report includes the following background on the concept of a work:

A work is an abstract entity; there is no single material object one can point to as the work. We recognize the work through individual realizations or expressions of the work, but the work itself exists only in the commonality of content between and among the various expressions of the work. . . Because the notion of a work is abstract, it is difficult to define precise boundaries for the entity. The concept of what constitutes a work and where the line of demarcation lies between one work and another may in fact be viewed differently from one culture to another. ${ }^{7}$

The difficulty in coming to a common agreement on what constitutes a work is seen in the different views expressed in a special issue of Cataloging \& Classification Quarterly that was devoted to the concept of a work in the modern catalog. ${ }^{8}$ Smiraglia, editor of the volume, also wrote a subsequent article in which he identifies critical elements of definitions of works by authors from Panizzi (1841) and onward. ${ }^{9}$ Views on the more specific concept of a serial work have been proposed by some authors, with an overview of some of these views following.

Some have taken a strong stand on the importance of the user's perceptions and needs in creating guidelines for recognizing new serial works. Layne and Antelman both note that neither the librarian nor library users would see a new work in the records created by cataloging rules. ${ }^{10}$ Antelman suggests that a new work identifier is needed for serials, since neither name nor title are reliable identifiers of a serial work. She proposes the concept of bibliographic families to group records for related serials in the library catalog. ${ }^{11}$

Yee and Kuhagen voice similar concerns, with Yee suggesting that not only could the title and author change, but the intellectual and artistic content could be changed without the serial becoming a new work. ${ }^{12}$ She proposes: "As a rule of thumb, consider two items to be the same work if they would be considered interchangeable by most users, or if a user seeking one would actually find the other preferable (as in the case of a later revised edition)." ${ }^{\prime 3}$ Kuhagen suggests that users' needs in finding and selecting serials would be best supported if serials with changed titles were treated as single works, whereas mergers and splits could be treated as different works. ${ }^{14}$ 
Adams and Santamauro take an approach similar to Antelman's, proposing that instead of identifying works, one should identify superworkspressions. ${ }^{15}$ This concept, derived from FRBR principles, draws on the work of Frieda Rosenberg and Diane Hillman. ${ }^{16}$ Adams and Santamauro suggest that an umbrella record could be created for each superworkspression, containing all of the bibliographic information pertaining to the resource regardless of format. Manifestation records, specific to particular formats, would stem from the umbrella record, with item records branching off from the manifestation record. The authors propose doing away with the current practice of successive entry cataloging, which requires a new record for every major change in title or format. New umbrella records would be created only when there has been a change in content. The authors acknowledge that it may prove difficult to determine when content has changed sufficiently to identify a new superworkspression. ${ }^{17}$

\section{History of Serials Cataloging Rules}

There has been a move, as cataloging rules have been revised, to require a new record or access point only when a new work has emerged. However, cataloging rules do not always include the guidance that could be provided by a specific definition of a work. A brief overview of the major cataloging conventions used for serials follows.

Hirons provides a succinct description of the three conventions that have been used historically for cataloging serials:

- Earliest entry: all changes are kept on a single record with the description based on the earliest issue and title changes, etc. recorded in notes;

- Latest entry: all changes are kept on a single record with description based on the latest (most recent) issue and earlier titles, etc. given in notes;

- Successive entry: a new record is made for each title or other major change (e.g., main entry); description is based on the latest issue (AACR1) or the earliest issue (AACR2). ${ }^{18}$

As Jones notes, different works will be identified for the same serial, depending on which of these conventions is applied. ${ }^{19}$

Both RDA and AACR2 are based on the concept of successive entry. ${ }^{20}$ There is continuing debate, however, on the merits of successive entry cataloging versus maintaining a single record or access point for serials with title changes. A special concern with successive entry is that excessive numbers of records or access points are often required. The single record approach is proposed by Lim as a way to limit the number of records created, with the suggestion that separate records be created for titles resulting from mergers or splits. ${ }^{21}$ Hirons and Graham believe that successive entry cataloging fills a need, but propose that new records be created only when there has been a substantial change in the serial. ${ }^{22}$ The pros and cons of successive versus latest entry cataloging are discussed in a collection of articles, edited by Mary Curran and titled "Mission Accomplished? A Symposium on Latest vs. Successive Entry." ${ }^{\text {"23 }}$ The four contributors conclude that a system solution is needed, either via FRBR or a next-generation catalog.

\section{Characteristics of Serials with Title Changes}

Cataloging rules, as noted above, employ varying procedures for determining when new records or access points should be created for serials with title changes. Before procedures can be developed, however, it seems that one must understand the changes that occur in serials when a title changes, so the procedures can specify the kinds of changes that would warrant the recognition of a new work. In a previous article, the author identified several studies that investigated the reasons for serial title changes, but found that none of the studies looked at how the information could be used to inform the task of creating or revising cataloging rules. A research study was therefore conducted by the author to identify the characteristics of serials with title changes, with the goal of providing input for improving cataloging rules. ${ }^{24}$ It was determined that 80.8 percent of the underlying changes that occur in serials with title changes are for subject or function changes. It was further determined that to identify new works for serials with title changes, using the FRBR concept of a work as a guide, a significant subject or function change must occur. The recognition that significant change must occur correlates with a comment by Adams and Santamauro that a sufficient change in content is needed for a new superworkspression record to be created..$^{25}$ How to recognize significant change in serials is a topic not addressed in these studies.

\section{Summary of the Literature}

In summary, there are differing views on what constitutes a serial work. Cataloging rules likewise differ in how a serial work is viewed, with some cataloging codes providing no definition of a work and no rationale for the access points and entries that are created. Some individuals who have commented on this issue believe that new records and access points for serials with title changes should be created only when there has been sufficient or substantial change in the serial. How to identify substantial change in a serial has not been addressed in the literature. 


\section{Method}

\section{Conceptual Framework}

The purpose of the study was to develop a means for identifying significant subject and function changes in serials with title changes and then to recommend changes in cataloging rules for recognizing new serial works. The research was descriptive and exploratory. The RDA definitions of a work and of a serial were used. Thus, a serial was defined as "a resource issued in successive parts, usually bearing numbering, that has no predetermined conclusion (e.g., a periodical, a monographic series, a newspaper)." ${ }^{26}$ A work, as previously noted, was defined as "a distinct intellectual or artistic creation (i.e., the intellectual or artistic content). ${ }^{{ }^{27} 7}$ This definition corresponds with the definition used in the FRBR model that forms the conceptual basis for the RDA rules. ${ }^{28}$ A subject change was defined as "a change in the serial's topical content" (e.g., a change from zoology to biology). A function change, in turn, was defined as "a change in the serial's character or purpose" (e.g., a change from a bulletin to a journal).

The goal of developing a means for identifying significant subject and function changes in serials with title changes was achieved by seeking answers to three questions:

- First, what are the broad subcategories into which subject and function changes in serials with title changes can be divided? It was assumed that the subcategories would provide a broad grouping of the kinds of changes that occur in serials with title changes. The subcategories could then be evaluated in the subsequent step.

- Second, what level of evidence is provided by each subcategory of subject and function change in recognizing a new serial work? It was expected that the assignment of a level to each subcategory would enable one to know how the changes represented by the subcategory would contribute to the recognition of a new work, with higher level changes contributing most. This information would provide a tool that could be used in the next step.

- Third, which of the subcategories, or combinations of subcategories, of subject and function change would provide evidence of a significant change, needed to recognize a new serial work? It was anticipated that the information gathered above could be used to develop various approaches for recognizing new works. An assumption was made that the approaches for identifying new works must be practical and cost effective, due to limited cataloging budgets.

In summary, the research questions were:
- What are the broad subcategories into which subject and function changes in serials with title changes can be divided?

- What level of evidence is provided by each subcategory of subject and function change in recognizing a new serial work?

- Which of the subcategories, or combinations of subcategories, of subject and function change provide evidence of a significant change, needed to recognize a new serial work?

\section{Sample}

The sample used in the study was from the author's previous study of serials with title changes mentioned above. This sample was chosen so the current study could enlarge on the recommendations made in the previous study. The sample was taken from JSTOR - short for Journal Storage (www. jstor.org) — an online database archive of full-text digitized back issues of academic journals, including various kinds of serials, such as bulletins, reviews, annuals, newsletters, yearbooks, and proceedings. Four JSTOR collections were included in the sample: Arts and Sciences I, Arts and Sciences II, Arts and Sciences III, and Life Sciences. These collections covered a variety of disciplines, including the humanities, social sciences, language, literature, and life sciences. Non-English serials were excluded, as were serials consisting of splits or mergers, since the latter were already considered to be different works and did not require further analysis. Serials for which no explanation of the title change was found in the text were also excluded, leaving 120 serials. In the current study, only the serials in which a subject or function change occurred, relevant to the title change, were considered. This caused twenty-three serials to be excluded, leaving ninety-seven serials in the final sample. The majority of the resulting serials were from the 1900s. A list of the serials is found in appendix A, by the title to which the serial was changed. Due to the nature of the sample, with a focus on academic serials, there may be limitations in generalizing the findings.

\section{Procedure for Identifying Subject and Function Subcategories}

The first research question was (A): What are the broad subcategories into which subject and function changes in serials with title changes can be divided? To answer this question, the descriptions of why titles change, identified in the previous study, were used. These descriptions were derived from statements occurring in the text of the serials. For example, the reason for a title change might have been due to a broadening of the subject content (e.g., from zoology to biology), or a change in function (e.g., from a newsletter to a journal). 
Some descriptions were reworded to create consistency for better grouping of the descriptions. Only the 179 descriptions relating to subject and function changes were examined. The following steps were performed:

1. Identified subject subcategories

- Created a list of all descriptions pertaining to subject changes in the serials

- Grouped the descriptions into subcategories based on the wording and intent of the descriptions (see appendix B)

2. Identified function subcategories

- Created a list of all descriptions pertaining to function changes in the serials

- Grouped the descriptions into subcategories based on the wording and intent of the descriptions (see appendix C)

In the initial attempt to develop subcategories for the subject and function changes, broad groupings were created, consisting of eight to ten subcategories of subject changes and eight to ten subcategories of function changes. The wording of the descriptions was used as much as possible to create the groupings. The resulting subcategories were later subdivided further so finer distinctions could be made, allowing greater flexibility for the evaluation of the subcategories in the following step.

Some descriptions did not group well with other descriptions. New subcategories were created for some of these unique descriptions, if the descriptions were different enough to warrant separate subcategories. Other unique descriptions were grouped with descriptions that seemed to represent a similar intent. The remaining unique descriptions were placed in a miscellaneous subcategory, along with a few general descriptions that described "new" or "additional" features. If a description referred to more than one type of change, the description was assigned to the subcategory corresponding with the first change mentioned, unless a subsequently described change was more specific.

\section{Procedure for Assigning Levels to the Subcategories}

The second research question was (B): What level of evidence is provided by each subcategory of subject and function change in recognizing a new serial work? To answer this question, the subcategories were classified according to the expected value of the changes in identifying a new work. The following steps were performed:

1. Assigned a level to each subject subcategory - Developed guidelines for assigning levels to the subject subcategories:
- High-level: (1) changed overall content of the serial

- Medium-level: (1) added or deleted certain subjects, (2) changed overall emphasis or focus, (3) increased/decreased emphasis on certain subject(s), or (4) brought title into harmony with the content of the serial

- Low-level: (1) brought title into harmony with the stated scope of the serial

- Assigned a level to each subject subcategory, along with a code (e.g., S1.1 for high, S2.1 for medium, S3.1 for low)

- Entered a code for each description associated with each serial in appendix A (column 3)

2. Assigned a level to each function subcategory

- Developed guidelines for assigning levels to the function subcategories:

- High-level: (1) changed overall function of the serial

- Medium-level: (1) added or deleted certain types of articles, (2) increased/decreased emphasis on certain types of articles, or (3) brought title into harmony with the types of articles published in the serial

- Low-level: (1) added, deleted, or changed sections or features in the serial

- Assigned a level to each function subcategory, along with a code (e.g., U1.1 for high, U2.1 for medium, U3.1 for low)

- Entered a code for each description associated with each serial in appendix A (column 3)

3. Assigned a primary level to each serial

- Assigned a primary level (high, medium, or low) to each serial, based on the highest level subcategory associated with the serial

- Recorded a term (high, medium, or low) for the primary level assigned to each serial in appendix A (column 4)

The FRBR guidelines for modified works, requiring a significant degree of change to recognize a new work, provided the basis for assigning the levels to the subcategories. The guidelines, developed by an IFLA Study Group on the Functional Requirements for Bibliographic Records, state: "By contrast, when the modification of a work involves a significant degree of independent intellectual or artistic effort, the result is viewed, for the purpose of this study, as a new work." ${ }^{29}$ Though the guidelines were not intended specifically for serials, the idea that significant effort or change must occur to recognize a new work was assumed to apply to any resource that has undergone change.

The task was to determine the kinds of subject and function changes that would be significant versus those that 
would not be significant. Five levels were used initially, but this proved to be too specific, so three three levels noted above were then used, which seemed sufficient to distinguish the subcategories. It was envisioned that the high-level subcategories would represent major changes, the mediumlevel subcategories would represent moderate changes, and the low-level subcategories would represent minor changes.

\section{Procedure for Recognizing New Works}

The third research question was (C): Which of the subcategories, or combinations of subcategories, of subject and function change provide evidence of a significant change, needed to recognize a new serial work? To answer this question, three approaches were developed, using the sampled serials to test each approach. The primary approach consisted of identifying serials with high-level subject or function changes. If a high-level change did not occur, two alternate approaches were tried, involving the identification of serials with medium-level subject or function changes. The steps taken with each approach are described below.

1. Primary approach: Identified high-level subject and function changes

- Identified all serials in appendix A (column 4) for which a high-level subject or function change occurred

- Determined the total number of serials for which a high-level change occurred

2. Alternate approach (1): Identified multiple mediumlevel subject or function changes

- Identified all serials in appendix A (column 3) that had multiple medium-level subject or function changes and no high-level change

$\circ$ Developed tests to determine which serials with multiple medium-level changes were potentially new works

3. Alternate approach (2): Identified successive medium-level subject or function changes

- Identified all serials in appendix A that had a succeeding title change

o Identified the serial sets that met the following conditions: (1) neither of the serials in the set had a high-level, and (2) each serial in the set had a single medium-level change

- Developed tests to determine which serials with successive title changes were potentially new works

It was assumed that the identification of high-level changes, in the primary approach above, would provide sufficient evidence for a new work, with no further testing required. However, for the alternate approaches, which used medium-level changes as evidence, a means was needed to determine whether the combined changes could be considered significant. Two tests were developed to evaluate these changes. The first test required three medium-level subject or function changes to occur, in any combination. The second test required two prioritized medium-level subject or function changes to occur. A list was created of medium-level subcategories representing prioritized changes, including four subject subcategories and four function subcategories. An attempt was made in creating the list to identify the subcategories that represented the greatest amount of change. The list was intended as a preliminary list, with modifications anticipated as the procedure was implemented and evaluated. The subcategories were the following:

S2.2 - Broadened content to include other subjects S2.5_ Changed overall emphasis or focus

S2.7-Narrowed content

S2.9-Brought title into harmony with content of serial

U2.9-Increased emphasis on original, scientific, or conceptual articles

U2.10-Increased emphasis on the peer review process

U2.11-Narrowed the article selection policy

U2.13-Brought title into harmony with types of articles published

\section{Results}

The findings from the study are reported here, relevant to the three tasks that were performed: (A) identifying subcategories, (B) assigning levels to the subcategories, and (C) developing procedures for recognizing new serial works.

\section{Identifying Subcategories}

The 179 descriptions of subject and function changes associated with the ninety-seven serials in the sample were grouped into thirty-five subcategories. The grouping resulted in the creation of thirteen subcategories pertaining to subject changes and twenty-two subcategories relating to function changes. The subject subcategories are listed in appendix B, along with descriptions of the associated subject changes, and the function subcategories and descriptions are listed in appendix C. There were eighty descriptions of subject changes in the sample and ninety-nine descriptions of function changes.

\section{Assigning Levels to the Subcategories}

Each subject and function subcategory identified above was assigned to one of three levels: high, medium, or low. 
Table 1 lists the subject subcategories assigned to each of the three levels, with table 2 listing the function subcategories assigned to each level. The eighty descriptions of subject changes were assigned as follows: twenty-one descriptions were assigned to a high-level subcategory, fifty-four to a medium-level subcategory, and five to a low-level subcategory. The ninety-nine descriptions of function changes were assigned as follows: seventeen descriptions were assigned to a high-level subcategory, forty-five to a medium-level subcategory, and thirty-seven to a low-level subcategory.

A primary level was assigned to each serial, based on the highest level subject or function subcategory associated with the serial. Over a third of the serials (36.1 percent) were classed with a primary level for a high-level change, over half (57.7 percent) with a primary level designating a mediumlevel change, and less than a tenth $(6.2$ percent) with a primary level for a lowlevel change.
Table 1. Subject Change Subcategories by Level of Evidence

\begin{tabular}{llc}
\hline Code & Subcategories by Level of Evidence & $\begin{array}{c}\text { No. of } \\
\text { Descriptions }\end{array}$ \\
\hline S1.1 & HIGH & 5 \\
S1.2 & Changed overall subject content & 7 \\
S1.3 & Broadened content to a more inclusive field(s) of study & 9 \\
& Broadened geographic coverage & 21 \\
\hline & Subtotal & \\
\hline S2.1 & MEDlUM & 9 \\
S2.2 & Added a subject(s) & 8 \\
S2.3 & Broadened content to include other subjects & 7 \\
S2.4 & Broadened content with more varied coverage & 9 \\
S2.5 & Changed content to reflect developments in the field & 4 \\
S2.6 & Changed overall emphasis or focus & 9 \\
S2.7 & Increased emphasis on a subject(s) & 1 \\
S2.8 & Narrowed content & Stopped covering a subject(s) \\
S2.9 & Brought title into harmony with content of serial & 2 \\
& Subtotal & 5 \\
\hline & LOW & 54 \\
\hline S3.1 & Brought title into harmony with stated scope of serial & 5 \\
& Subtotal & \\
\hline
\end{tabular}

\section{Developing Procedures for Recognizing New Serial Works}

The findings from the foregoing tasks were used to develop procedures for recognizing new serial works. Three approaches were developed, including a primary approach and two alternate approaches. The serials in the sample were used to test each approach, with the results from the testing described below.

The primary approach for recognizing a new serial work consisted of identifying a high-level subject or function change in the serial. Tables 1 and 2 contain respective displays of the high-level subcategories of subject and function changes found in the study. The descriptions associated with each subcategory are listed in the appendixes, with appendix B providing descriptions of the high-level subject changes and appendix $\mathrm{C}$ providing descriptions of the high-level function changes. The ninety-seven serials in the sample had thirty-five changes falling into a high-level subject or function subcategory, not counting three duplicate changes. Two serials (no. 85 and no. 95) had subject changes falling into two different subcategories. Also, one serial (no. 1) had both a high-level subject change and a high-level function change. When excluding the duplicate subject changes, about half of the high-level changes (nineteen) were subject changes, and the other half (seventeen) were function changes. Close to a third (29.2 percent) of the 120 serials in the original sample, from which the current sample was taken, were identified as new works using the foregoing approach.

The first alternate approach that was tried for identifying new works considered the evidence provided by multiple medium-level changes in the serials. Only those serials were examined that were not already identified with a high-level change. Of the sixty-two serials not identified with a highlevel change, seventeen had multiple medium-level changes. A total of forty-four medium-level changes occurred in the seventeen serials, including nineteen function changes and twenty-five subject changes. For close to two-thirds of the serials (eleven), two medium-level changes occurred, and for close to one-fourth of the serials (four), three mediumlevel changes occurred. The remaining two serials had four or six medium-level changes each.

To evaluate this approach, two tests were developed to set limits on the combination of medium-level changes that would qualify a serial as a new work. The results from applying Test 1, requiring three medium-level subject or function changes to occur, are found in table 3. This test resulted in six of the seventeen serials qualifying as new works. The results from applying Test 2, requiring 
two prioritized medium-level subject or function changes to occur, are reported in table 4. This test resulted in three of the seventeen serials qualifying as new works. More new works were thus identified with the first test. The new works identified with each test were different, except for one serial (no. 112) which qualified under both tests.

The second alternate approach used to identify new works considered the evidence provided by cumulative change in serials that had a succeeding title change. The sample included nine sets of serials with a succeeding title change, with each set consisting of two title changes. The goal was to identify any set for which new works had not already been identified with the previous approaches. The sets are listed in table 5. Two sets were eliminated due to a high-level change occurring in one or both of the serials in the set. Three additional sets were eliminated because at least one of the serials had multiple medium-level changes. In the one remaining set (set 6), there was a single medium-level change in each of the serials comprising the set.

To evaluate this approach for its value in identifying new works, Test 2 , above, requiring two prioritized changes to occur, was used. Test 1 , requiring three medium-level changes to occur, could not be used since only two changes occurred in the set. When applying Test 2, both of the changes that occurred qualified as prioritized changes, as follows:

S2.2 - Broadened the scope of the Federation and the Journal to cover all waste control problems, including more space given to industrial waste papers in relation to papers on municipal sewage works problems (no. 114)

S2.2-Broadened responsibility of the Federation and the Journal to cover water pollution control (no. 113)

\section{Summary of Results}

A summary of the results when applying the three approaches to recognize new works is provided in table 6 . The primary approach, using only high-level subject or function
Table 2. Function Change Subcategories by Level of Evidence

\begin{tabular}{|c|c|c|}
\hline Code & Subcategories by Level of Evidence & $\begin{array}{c}\text { No. of } \\
\text { Descriptions }\end{array}$ \\
\hline & $\mathrm{HIGH}$ & \\
\hline \multirow[t]{3}{*}{$\mathrm{U} 1.1$} & Changed overall function of serial & 17 \\
\hline & Subtotal & 17 \\
\hline & MEDIUM & \\
\hline $\mathrm{U} 2.1$ & Began including authoritative articles on special topics & 2 \\
\hline $\mathrm{U} 2.2$ & Began including commentaries & 3 \\
\hline $\mathrm{U} 2.3$ & Began including conference or symposia papers or plans & 3 \\
\hline $\mathrm{U} 2.4$ & Began including literature reviews or review articles & 9 \\
\hline $\mathrm{U} 2.5$ & Began including non-conference articles & 2 \\
\hline $\mathrm{U} 2.6$ & Began including reports & 2 \\
\hline $\mathrm{U} 2.7$ & Began publishing original, scholarly, or research articles & 9 \\
\hline $\mathrm{U} 2.8$ & Developed or expanded upon a function & 4 \\
\hline $\mathrm{U} 2.9$ & Increased emphasis on original, scientific, or conceptual articles & 3 \\
\hline $\mathrm{U} 2.10$ & Increased emphasis on the peer review process & 4 \\
\hline $\mathrm{U} 2.11$ & Narrowed the article selection policy & 1 \\
\hline $\mathrm{U} 2.12$ & Stopped including a function & 1 \\
\hline \multirow[t]{3}{*}{$\mathrm{U} 2.13$} & Brought title into harmony with types of articles published & 2 \\
\hline & Subtotal & 45 \\
\hline & LOW & \\
\hline $\mathrm{U} 3.1$ & Added a bibliography section & 2 \\
\hline $\mathrm{U} 3.2$ & Added a book review section & 2 \\
\hline $\mathrm{U} 3.3$ & Added a commentary, discussion, or debate section & 7 \\
\hline U3.4 & Added a correspondence section & 4 \\
\hline U3.5 & Added a news section & 3 \\
\hline U3.6 & Added a notes section & 4 \\
\hline $\mathrm{U} 3.7$ & Added abstracts, resumes, or other new features & 5 \\
\hline \multirow[t]{2}{*}{$\mathrm{U} 3.8$} & Changed or updated a section or feature & 10 \\
\hline & Subtotal & 37 \\
\hline
\end{tabular}

changes to recognize a new work, resulted in thirty-five new works being identified in the ninety-seven serials examined. When also using the two alternate approaches, the number of new works potentially identified increased. The first alternate approach, requiring multiple medium-level changes to occur, resulted in either three or six additional new works being identified, depending on which limiting procedure was used. The second alternate approach, requiring cumulative medium-level changes to occur over a range of title changes, resulted in one additional new work being identified. When using all three approaches, a maximum of forty-two of the ninety-seven serials were potentially identified as new works. When considering the original sample of 120 serials, the percent of serials potentially identified as new works 
Table 3. Medium-Level Changes: Minimum of Three

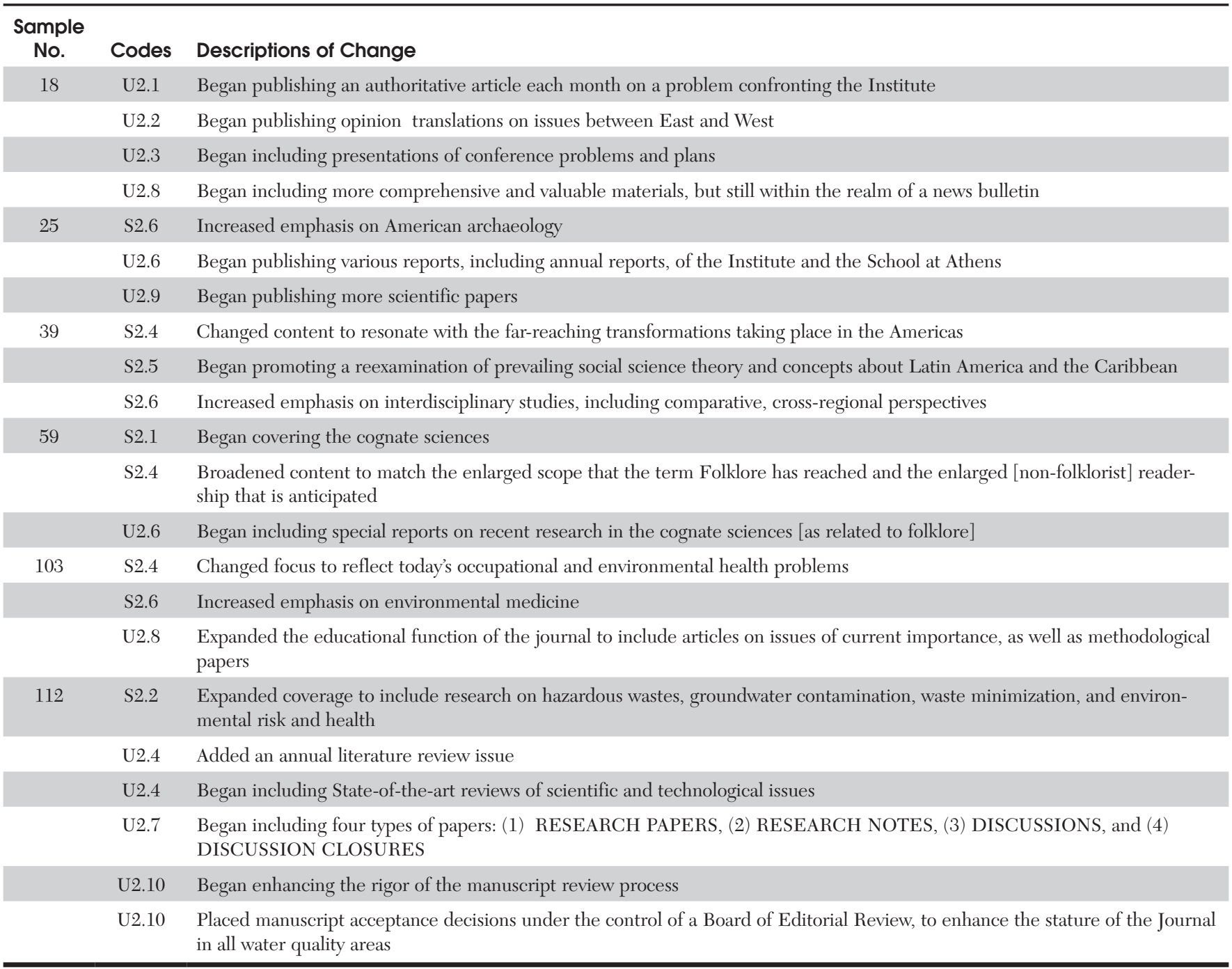

Table 4. Medium-Level Changes (Prioritized): Minimum of Two

\begin{tabular}{|c|c|c|}
\hline $\begin{array}{l}\text { Sample } \\
\text { No. }\end{array}$ & Codes & Descriptions of Change (Prioritized) \\
\hline \multirow[t]{2}{*}{52} & S2.2 & $\begin{array}{l}\text { Broadened content to include art education (providing information, presenting theories and criticisms, announcing opportuni- } \\
\text { ties and resources, and promoting discussion relating to art education) }\end{array}$ \\
\hline & S2.2 & Broadened discussion beyond problems concerning the history of art [a major purpose of journal is discussion] \\
\hline \multirow[t]{2}{*}{66} & $\mathrm{U} 2.9$ & $\begin{array}{l}\text { Increased preference for original contributions on treatment and research in all branches of the theory and practice of the con- } \\
\text { servation of cultural property, as well as contributions in art history and science }\end{array}$ \\
\hline & $\mathrm{U} 2.10$ & Increased emphasis on the peer review process by excluding preprint volumes as published volumes of the journal \\
\hline \multirow[t]{3}{*}{112} & S2.2 & $\begin{array}{l}\text { Expanded coverage to include research on hazardous wastes, groundwater contamination, waste minimization, and environ- } \\
\text { mental risk and health }\end{array}$ \\
\hline & $\mathrm{U} 2.10$ & Began enhancing the rigor of the manuscript review process \\
\hline & $\mathrm{U} 2.10$ & $\begin{array}{l}\text { Placed manuscript acceptance decisions under the control of a Board of Editorial Review, to enhance the stature of the Journal } \\
\text { in all water quality areas }\end{array}$ \\
\hline
\end{tabular}


using the primary approach was 29.2 percent (35/120), and when also using the two alternate approaches the percent increased to a maximum of 35.0 percent (42/120).

\section{Discussion of Findings}

This study was different from previous studies of serials with title changes in that the focus was on subject and function changes, rather than on the full array of changes that might occur when a title changes. Thus no comparison of findings can be made with previous studies. The limitations of the study are discussed below, including comments about potential bias and to what extent the findings can be generalized. Issues involved in using the findings to recognize new serial works are also discussed.

There was potential bias in the way the descriptions were grouped into subcategories, despite relying on common word usage in the grouping, since some descriptions could not be readily grouped based on word usage. By expanding the number of subcategories, the problem was lessened, with fewer descriptions requiring special handling. There was also potential bias in assigning levels to the subcategories. For example, the subcategory "Broadened geographic coverage" might have been classed as a medium-level change rather than a high-level change. Likewise, some subcategories assigned as medium-level subcategories could possibly have been classed as high-level subcategories, for example: "Narrowed content," "Narrowed the article selection policy," and "Increased emphasis on original, scientific, or conceptual articles." The assignment of levels to the subcategories was preliminary and not a final determination of how the various subcategories should be treated.

The findings from the study can be generalized to academic serials, from which the sample was drawn. The findings should also have relevance to other types of serials, though the thirty-five subcategories identified in the study may not be as comprehensive as needed to categorize the full range of changes that might occur in a collection of both academic and nonacademic serials. A study of nonacademic serials is needed to determine whether additional subcategories would be needed for these serials.

Various approaches might have been taken in developing the procedures for recognizing new works. The three approaches chosen seemed logical in light of the data available and the need to be practical. The primary approach, requiring the occurrence of a high-level change in the serial, was the preferred approach. Whether one would also use alternate approaches would depend on how broadly or narrowly the concept of significant change is interpreted. With a narrow interpretation, only the primary approach would be appropriate. With a broader interpretation, the alternate approaches might also be used. These decisions would have to be made by the serials community. The pros and cons of each approach are discussed below.

Table 5. Successive Medium-Level Changes

\begin{tabular}{ccll}
\hline Set No. & $\begin{array}{c}\text { Sample } \\
\text { No. }\end{array}$ & Subcategory Codes & $\begin{array}{l}\text { Primary Level } \\
\text { of Evidence }\end{array}$ \\
\hline 1 & 34 & $\mathrm{U} 1.2 \mathrm{U} 3.8$ & high \\
high
\end{tabular}

Table 6. Approaches for Identifying New Serial Works

\begin{tabular}{|c|c|c|c|}
\hline Approach & Changes Required by the Approach & $\begin{array}{l}\text { New Works Identified } \\
(N=120)^{*}\end{array}$ & Percent \\
\hline Primary approach & One high-level change & 35 & 29.2 \\
\hline Alternate approach (1a) & Three medium-level changes & $6(\mathrm{a})$ & $5.0(\mathrm{a})$ \\
\hline Alternate approach (1b) & Two medium-level changes (prioritized) & $3(\mathrm{~b})$ & $2.5(b)$ \\
\hline Alternate approach (2) & $\begin{array}{l}\text { Two medium-level changes } \\
\text { (succeeding, prioritized) }\end{array}$ & 1 & 0.8 \\
\hline Total & & $\begin{array}{l}42(\mathrm{a}) \\
39(\mathrm{~b})\end{array}$ & $\begin{array}{l}35.0(\mathrm{a}) \\
32.5(\mathrm{~b})\end{array}$ \\
\hline
\end{tabular}

* "N" represents the number of serials in the original sample from which the current sample was taken. 
The primary approach required a high-level subject or function change to occur. Pros and cons of this approach include the following:

- Pros: This would be the most reliable approach for identifying new serial works, since only a major change would qualify a serial as a new work. It is also expected to be the easiest to apply, since one would look for only a few types of changes in the serial, falling within the four high-level subject or function subcategories.

- Cons: The effectiveness of this approach would depend on how accurately the high-level subcategories have been identified.

The first alternate approach required multiple mediumlevel subject or function changes to occur. Some pros and cons of this approach would be the following:

- Pros: This approach would provide a way to potentially identify more new works than if just the primary approach were used.

- Cons: This approach may yield incorrect results, since a combination of moderate changes may not be sufficient to determine that a significant change has occurred. The limiting procedures may incorrectly determine that substantial change has occurred. The time required to look for the many kinds of mediumlevel changes in the serials and then apply the limiting procedures would also have to be considered.

The second alternate approach required successive medium-level subject or function changes to occur. Some pros and cons of this approach would be the following:

- Pros: This approach would provide a way to potentially identify more new works than if just the primary approach and the first alternate approach were used. A possible advantage of this approach over the previous alternate approach would be that more change may occur over a span of title changes than one might find in a single title change. In the one example found in the sample, there seemed to be a progression of change from one title change to the next.

- Cons: This approach may yield incorrect results, since the combination of changes may not be sufficient to be considered significant. The limiting procedures may, as above, incorrectly determine that substantial change has occurred. One would also have to consider whether a new work should be identified over a range of title changes, as well as the need to keep track of changes occurring over multiple title changes. Since only one potential new work was identified in the sample, this approach may not be worth considering, though in a larger sample more new works might have been recognized.

In summary, each of the three approaches for identifying new works has advantages and disadvantages. The primary approach, requiring high-level changes to occur, would be the most straightforward to apply and would yield the best results. The two alternate approaches, using mediumlevel changes, would require time to look for the various kinds of changes in the serials and then to apply the limiting procedures. This may not be practical in a cataloging environment. One would also have to consider how strictly to interpret the concept of significant change in serials and whether the goal should be to limit the number of new works identified or to expand the number. These issues will require discussion by the serials community.

\section{Recommendations}

The purpose of the study was to develop a means for identifying significant subject and function changes in serials with title changes and then to recommend changes in cataloging rules for recognizing new serial works. A previous study recommended that a new work should be recognized only when a significant subject or function change has occurred. The current study enlarges upon this by providing a way to determine when a significant change has occurred.

Since the study showed that high-level subject and function changes provide the best evidence for significant change in serials with title changes, it is recommended that the four high-level subject and function changes identified in the study be used to recognize new works. Whether multiple medium-level changes should also be treated as significant was not conclusively determined in the study. It is recommended that the serials community evaluate the study's findings concerning both the high-level changes and the medium-level changes to determine whether broadening or narrowing of the assigned levels should be made and whether multiple medium-level changes should be considered as evidence for a significant change. Pending these discussions, a narrow interpretation of significant change is assumed in the recommendations that follow.

The recommendations that follow are specific to cataloging rules based on FRBR concepts, in particular the RDA rules, since the study used FRBR guidelines in the development of the procedures. The recommendations will have most relevance to academic serials, due to limitations in the sample, but the recommendations are broad enough to also have potential application to nonacademic serials. The recommendations are, moreover, specific to serials with title changes and do not cover serials with other types of changes, 
such as a change in responsibility.

Given the above limitations, it is recommended that the RDA rules for creating new access points for serials with title changes be modified to incorporate the changes described below. In particular, the following rules should be changed: RDA rule 6.1.3.2.2, titled "Major change in the title proper," along with RDA rule 2.3.2.13, titled "Major and minor changes in the title proper of serials." ${ }^{.30}$ The elements that should be incorporated include the following:

1. Determine the reason for the title change by using one of the following sources of information, in the following order:

- An explanation provided in the first issue of the serial with the new title (or a subsequent issue, if needed)

- An explanation provided by the publisher, editor, or sponsoring agency of the serial

- An explanation from another external source explaining why the title changed

o Words in the title

2. Create a new access point for a work when the reason for the title change meets one of the following conditions:

- There has been a significant change in the subject content of the serial, as evidenced by a change in one of the following subcategories: (1) changed overall subject content, (2) broadened content to a more inclusive field(s) of study, or (3) broadened geographic coverage (see appendix B for examples).

- There has been a significant change in the function of the serial, as evidenced by a change in the following subcategory: (1) changed overall function of serial (see appendix $\mathrm{C}$ for examples).

\section{Conclusion and Further Research}

The object of the study was to propose RDA cataloging rule changes for serials with title changes. Preliminary recommendations are made, pending additional research and testing. Some of the areas in which additional study is needed are described here.

The primary area in which additional research should be undertaken is with regard to title changes in nonacademic serials. It would be useful to collect information paralleling what was found for academic serials, including the identification of the subcategories of subject and function changes that occur in nonacademic serials with title changes. These findings could be used to broaden the recommendations in the current study to apply to both academic and nonacademic serials.
There is a further need to seek input from the serials community on the recommended rule changes, especially concerning the dividing point between a medium-level change and a high-level change. The community should also consider whether multiple medium-level changes would provide sufficient evidence for identifying a new work or if only high-level changes should be considered.

The proposed rule changes should be tested in a cataloging environment. Testing would help to determine whether the rule changes are practical for a working environment and where clarification is needed. There is also a need to determine the practicality of seeking input from publishers, editors, and sponsoring agencies when the reason for a title change is not found in the serial itself. It would be helpful to know the amount of time required to contact publishers and others, as well as the success rate in obtaining the needed information.

The recommendations made in the study provide a strong foundation for improving the RDA cataloging rules. The additional research and testing proposed here could be used to refine the recommendations further and ensure that the suggested changes will work well in today's cataloging environment.

\section{References}

1. Jean L. Hirons, "Reflections on Seriality," Serials Librarian 43, no. 2 (2002): 134; CONSER Cataloging Manual, 2002 ed. (Washington, DC: Library of Congress, Cataloging Distribution Service, 2002-), section 16.2.1, accessed October 19, 2012, http://desktop.loc.gov.

2. IFLA Study Group on the Functional Requirements for Bibliographic Records, Functional Requirements for Bibliographic Records: Final Report, amended and corrected through February 2009 (The Hague: International Federation of Library Associations and Institutions, September 1997), 13, accessed October 19, 2012, www.ifla.org/files/cataloguing/frbr/frbr_2008.pdf.

3. RDA: Resource Description and Access (Chicago: American Library Association, 2010-), glossary, accessed October 19, 2012, www.rdatoolkit.org.

4. Anglo-American Cataloguing Rules, 2nd ed., 2002 rev., 2005 update (Chicago: ALA, 2002-5), rule 21.2C1, accessed October 19, 2012, http://desktop.loc.gov.

5. RDA, rules 1.6.2 and 6.1.3.2.

6. Mavis B. Molto, "Characteristics of Serial Title Changes and Recognition of New Serial Works: Theoretical and Practical Implications," Serials Review 37, no. 4 (2011): 275-89.

7. IFLA Study Group, Functional Requirements for Bibliographic Records, 17.

8. Richard P. Smiraglia, "Further Reflections on the Nature of 'a Work': An Introduction," Cataloging \& Classification Quarterly 33, no. 3/4 (2002): 1-11. 
9. Richard P. Smiraglia, "The History of 'the Work' in the Modern Catalog," Cataloging \& Classification Quarterly 35, no. 3/4 (2003): 558.

10. Sara Shatford Layne, email message, October 31, 1995, quoted in Jean L. Hirons, "Reflections on Seriality," Serials Librarian 43, no. 2 (2002): 134; Kristin Antelman, "Identifying the Serial Work as a Bibliographic Entity," Library Resources \& Technical Services 48, no. 4 (Oct. 2004): 239.

11. Antelman, "Identifying the Serial Work as a Bibliographic Entity," 238-44.

12. Martha M. Yee, "What Is a Work?" in The Principles and Future of AACR: Proceedings of the International Conference on the Principles and Future Development of AACR, ed. Jean Weihs, 82-83 (Ottawa: Canadian Library Association, 1998).

13. Yee, "What Is a Work?" 83.

14. Judith A. Kuhagen, "Modeling Continuing Resources in FRBR [and more]" (PowerPoint presentation, FRBR Workshop-OCLC, May 2, 2005), slides 12-13, accessed October 19, 2012, www.oclc.org/research/events/frbr-workshop/presentations/kuhagen/Kuhagen_OCLC_FRBR.ppt.

15. Katherine Adams and Britta Santamauro (Kurt Blythe, recorder), "Successive Entry, Latest Entry, or None of the Above? How the MARC21 Format, FRBR and the Concept of a Work Could Revitalize Serials Management," Serials Librarian 54, no. 3/4 (2008): 193-97.

16. Frieda Rosenberg and Diane Hillman, "An Approach to Serials with FRBR in Mind: CONSER Task Force on Universal Holdings," 2004, accessed October 19, 2012, www.lib.unc .edu/cat/mfh/serials_approach_frbr.pdf.

17. Adams and Santamauro, "Successive Entry, Latest Entry, or
None of the Above?" 197.

18. Hirons, "Reflections on Seriality," 130-31.

19. Ed Jones, "The FRBR Model as Applied to Continuing Resources," Library Resources \& Technical Services 49, no. 4 (Oct. 2005): 232.

20. Diane Boehr, Regina Romano Reynolds, and Tina Shrader, “The U.S. RDA Test Process," Serials Librarian 62, no. 1/4 (2012): 136.

21. Sue C. Lim, "Successive Entry Serials Cataloging: An Evaluation," Serials Librarian 14, no. 1/2 (1988): 64.

22. Crystal Graham, "What's Wrong with AACR2: A Serials Perspective," in The Future of the Descriptive Cataloging Rules, ed. Brian E. C. Schottlaender, 76-77 (Chicago: ALA, 1998); Jean L. Hirons and Crystal Graham, "Issues Related to Seriality," in The Principles and Future of AACR: Proceedings of the International Conference on the Principles and Future Development of AACR, ed. Jean Weihs, 204 (Chicago: ALA, 1998).

23. Mary Curran, introduction to "Mission Accomplished? A Symposium on Latest vs. Successive Entry," ed. Mary Curran, Serials Librarian 53, no. 1/2 (2007): 55-56.

24. Molto, "Characteristics of Serial Title Changes and Recognition of New Serial Works," 275-89.

25. Adams and Santamauro, "Successive Entry, Latest Entry, or None of the Above?" 197.

26. RDA, glossary.

27. Ibid.

28. IFLA Study Group, Functional Requirements for Bibliographic Records, 13, 17.

29. Ibid., 18.

30. $R D A$, rule 6.1.3.2.2 and rule 2.3.2.13.

\section{Appendix A. Sample of Serials with Title Changes*}

\begin{tabular}{|c|c|c|c|}
\hline $\begin{array}{l}\text { Sample } \\
\text { No. }\end{array}$ & New Title** & $\begin{array}{l}\text { Subject \& Function } \\
\text { Subcategory Codes }\end{array}$ & $\begin{array}{r}\text { Primary Leve } \\
\text { of Evidence }\end{array}$ \\
\hline \multicolumn{4}{|c|}{ JSTOR Arts and Sciences I Collection } \\
\hline 2 & (2) American journal of political science (1973-2006) & S1.3 & high \\
\hline 6 & (2) Current anthropology (1959-1999) & $\mathrm{U} 1.2$ & high \\
\hline 9 & (2) The journal of American history (1964-2002) & $\mathrm{S} 1.3$ & high \\
\hline 10 & (2) Journal of economic literature (1969-2005) & $\mathrm{U} 2.7$ & medium \\
\hline 11 & (2) Journal of health and social behavior (1967-2005) & S1.1 & high \\
\hline 13 & (4) Journal of the Royal Statistical Society. Series A (Statistics in society) (1988-2003) & S2.5 & medium \\
\hline 17 & (3) Nineteenth-century literature (1986-2004) & $\mathrm{S} 1.2$ & high \\
\hline
\end{tabular}




\section{Appendix A. Sample of Serials with Title Changes (cont.)*}

\begin{tabular}{|c|c|c|c|}
\hline $\begin{array}{l}\text { Sample } \\
\text { No. }\end{array}$ & New Title** & $\begin{array}{l}\text { Subject \& Function } \\
\text { Subcategory Codes }\end{array}$ & $\begin{array}{l}\text { Primary Level } \\
\text { of Evidence }\end{array}$ \\
\hline 18 & (2) Pacific affairs (1928-2002) & U2.1 U2.2 U2.3 U2.8 & medium \\
\hline 19 & (2) Perspectives on sexual and reproductive health (2002-2006) & S2.1 S2.6 & medium \\
\hline 20 & (2) Population (English edition) (2002-2005) & $\mathrm{U} 1.1$ & high \\
\hline 22 & (2) Social psychology (1978) & S1.1 & high \\
\hline \multicolumn{4}{|c|}{ JSTOR Arts and Sciences II Collection } \\
\hline 23 & (2) African affairs (1944-1999) & $\mathrm{U} 2.13$ & medium \\
\hline 24 & (2) African studies review (1970-2004) & $\mathrm{U} 2.7$ & medium \\
\hline 25 & (2) American journal of archaeology (1897-2002) & S2.6 U2.6 U2.9 & medium \\
\hline 26 & (2) Biometrics (1947-2002) & $\mathrm{U} 1.2$ & high \\
\hline 27 & (2) British journal of Middle Eastern studies (1991-2004) & $\mathrm{U} 1.2$ & high \\
\hline 28 & (2) Canadian journal of African studies (1967-2004) & $\mathrm{U} 1.2 \mathrm{U} 2.7$ & high \\
\hline 29 & (2) The Canadian journal of economics and political science (1935-1967) & S2.1 & medium \\
\hline 30 & (2) Europe-Asia studies (1993-2004) & S1.3 & high \\
\hline 31 & (4) Geographical review (1916-2002) & S2.3 U2.7 & medium \\
\hline 32 & (2) History of education quarterly (1961-2002) & $\mathrm{U} 2.8$ & medium \\
\hline 33 & (5) International affairs (Royal Institute of International Affairs) (1944-2002) & $\mathrm{U} 1.2$ & high \\
\hline 34 & (4) International affairs review supplement (1940-1943) & $\mathrm{U} 1.2 \mathrm{U} 3.8$ & high \\
\hline 35 & (2) International migration review (1966-2002) & $\mathrm{U} 2.7$ & medium \\
\hline 36 & (2) Background (1962-1966) & $\mathrm{U} 2.8$ & medium \\
\hline 37 & (3) Journal of marriage and the family (1964-2002) & U2.4 U3.7 U3.8 U3.8 & medium \\
\hline 38 & (3) Journal of Near Eastern Studies (1942-2002) & S2.4 & medium \\
\hline 39 & (3) Latin American politics and society (2001-2004) & $\begin{array}{l}\text { S2.4 S2.5 S2.6 U3.2 } \\
\text { U3.3 U3.3 U3.6 }\end{array}$ & medium \\
\hline 40 & (2) Journal of interamerican studies and world affairs (1970-2000) & $\mathrm{S} 1.3$ & high \\
\hline 41 & (2) National mathematics magazine (1934-1945) & $\mathrm{U} 2.13$ & medium \\
\hline 42 & (2) Medical anthropology quarterly (1983-2000) & S2.4 U3.7 U3.7 U3.8 & medium \\
\hline 44 & (2) Newsletter on science, technology, \& human values (1976-1978) & S2.5 U3.1 U3.5 & medium \\
\hline 45 & (2) Sixteenth century journal (1972-2002) & $\mathrm{U} 2.5$ & medium \\
\hline 46 & (4) Slavic review (1961-2006) & $\mathrm{U} 3.3$ & low \\
\hline 48 & (3) Transactions of the American Philological Association (1974-2000) & $\mathrm{U} 2.12$ & medium \\
\hline 49 & (3) Transactions of the Institute of British Geographers (1965-2002) & $\mathrm{U} 2.4 \mathrm{U} 3.4$ & medium \\
\hline \multicolumn{4}{|c|}{ JSTOR Arts and Sciences III Collection } \\
\hline 51 & (2) The bulletin of the College Art Association of America (1917-1918) & $\mathrm{U} 3.7$ & low \\
\hline 52 & (2) College art journal (1941-1960) & S2.2 S2.2 U3.2 U3.5 & medium \\
\hline 53 & (3) Asian ethnology (2008-2009) & $\mathrm{S} 1.2 \mathrm{~S} 2.9$ & high \\
\hline 54 & (2) The Burlington magazine (1948-2002) & S2.1 S2.9 & medium \\
\hline 55 & (2) Contemporary literature (1968-2004) & S3.1 U3.4 & low \\
\hline 56 & (2) Ethnomusicology forum (2004) & S2.3 & medium \\
\hline 57 & (3) Film quarterly (1958-2004) & S2.4 U3.4 U3.5 U3.6 & medium \\
\hline 59 & (3) Folklore (1890-2002) & S2.1 S2.4 U2.6 U3.1 & medium \\
\hline 61 & (2) Journal of African cultural studies (1998-2003) & S2.8 & medium \\
\hline 62 & (3) Journal of architectural education (1984-1997) & $\mathrm{U} 1.2$ & high \\
\hline
\end{tabular}




\section{Appendix A. Sample of Serials with Title Changes (cont.)*}

\begin{tabular}{|c|c|c|c|}
\hline $\begin{array}{l}\text { Sample } \\
\text { No. }\end{array}$ & New Title** & $\begin{array}{l}\text { Subject \& Function } \\
\text { Subcategory Codes }\end{array}$ & $\begin{array}{l}\text { Primary Level } \\
\text { of Evidence }\end{array}$ \\
\hline 63 & (3) The Old and New Testament student (1889-1892) & S2.6 S2.9 & medium \\
\hline 64 & (2) The Old Testament student (1883-1889) & S2.6 S3.1 & medium \\
\hline 65 & (2) Journal of Bible and religion (1937-1966) & $\mathrm{S} 1.2$ & high \\
\hline 66 & (3) Journal of the American Institute for Conservation (1977-2004) & $\mathrm{U} 2.9 \mathrm{U} 2.10$ & medium \\
\hline 68 & (2) Journal of the American Musicological Society (1948-2004) & $\mathrm{U} 2.11$ & medium \\
\hline 69 & (2) The journal of the Society of Architectural Historians (1945-2004) & $\mathrm{U} 3.8$ & low \\
\hline 70 & (3) Latin American music review / Revista de Música Latinoamericana (1980-2004) & S2.5 & medium \\
\hline 71 & (2) Anuario Interamericano de Investigacion Musical (1970-1975) & S2.3 S2.6 & medium \\
\hline 72 & (2) The musical times (1903-2004) & U3.4 U3.8 U3.8 U3.8 & low \\
\hline 73 & (2) PAJ: A journal of performance and art (1998-2002) & S2.1 S2.6 U3.6 & medium \\
\hline 74 & (2) Recent acquisitions (Metropolitan Museum of Art) (1985-1987) & S2.4 & medium \\
\hline 75 & (3) Rocky Mountain review of language and literature (1975-2006) & S2.9 U1.2 & high \\
\hline 76 & (2) South central review (1984-2003) & $\mathrm{U} 2.7$ & medium \\
\hline 77 & (2) Theatre journal (1979-1995) & S2.3 S3.1 & medium \\
\hline 79 & (2) Yearbook of the International Folk Music Council (1969-1980) & $\mathrm{U} 1.2$ & high \\
\hline \multicolumn{4}{|c|}{ JSTOR Life Sciences Collection } \\
\hline 80 & (2) Arctic, Antarctic, and alpine research (1999-2004) & S1.3 S2.1 S2.6 U2.4 & high \\
\hline 82 & (2) Clinical infectious diseases (1992-2004) & $\mathrm{U} 1.2 \mathrm{U} 2.1 \mathrm{U} 2.2$ & high \\
\hline 84 & (2) Diversity and distributions (1998-2001) & S2.1 & medium \\
\hline 85 & (2) Ecography (1992-2000) & S1.2 S1.3 S2.4 U3.6 & high \\
\hline 86 & (2) Epidemiology and infection (1987-2002) & S2.7 U2.4 & medium \\
\hline 87 & (2) Estuaries (1978-2002) & S1.3 U2.4 & high \\
\hline 89 & (2) Folia geobotanica (1998-2004) & U2.3 U3.3 & medium \\
\hline 90 & (2) Global ecology and biogeography (1999-2001) & S1.1 U2.7 & high \\
\hline 91 & (2) Infection control and hospital epidemiology (1988-2004) & S2.2 U3.3 & medium \\
\hline 92 & (2) Integrative and comparative biology (2002) & S2.4 & medium \\
\hline 93 & (3) International journal of plant sciences (1992-2002) & $\mathrm{U} 2.2$ & medium \\
\hline 94 & (4) Invertebrate biology (1995-2002) & S1.1 & high \\
\hline 95 & (2) Journal of avian biology (1994-2000) & S1.2 S1.3 S2.9 U3.3 U3.3 & high \\
\hline 96 & (3) Journal of avian medicine and surgery (1995-2006 ) & S2.1 S3.1 U3.8 & medium \\
\hline 97 & (2) Journal of the Association of Avian Veterinarians (1989-1994) & $\mathrm{U} 1.2$ & high \\
\hline 98 & (3) Journal of epidemiology and community health (1978) & S2.2 U2.4 & medium \\
\hline 101 & (2) Journal of the Torrey Botanical Society (1997-2004) & $\mathrm{U} 1.2$ & high \\
\hline 102 & (2) Micropaleontology (1955-2004) & S1.1 & high \\
\hline 103 & (2) Occupational and environmental medicine (1994-2006) & S2.4 S2.6 U2.8 U3.8 & medium \\
\hline 104 & (7) Philosophical transactions: biological sciences (1990-2004) & S2.3 & medium \\
\hline 106 & (6) Proceedings: biological sciences (1990-2004) & S2.3 U2.9 & medium \\
\hline 107 & (6) Proceedings: mathematical and physical sciences (1990-1995) & S2.3 & medium \\
\hline 108 & (2) Systematic biology (1992-2004) & $\mathrm{S} 1.2 \mathrm{U} 2.3 \mathrm{U} 2.4$ & high \\
\hline 112 & (4) Research journal of the Water Pollution Control Federation (1989-1991) & $\begin{array}{l}\text { S2.2 U2.4 U2.4 U2.7 } \\
\text { U2.10 U2.10 }\end{array}$ & medium \\
\hline
\end{tabular}




\section{Appendix A. Sample of Serials with Title Changes (cont.)*}

\begin{tabular}{llll}
$\begin{array}{c}\text { Sample } \\
\text { No. }\end{array}$ & \multicolumn{1}{c}{ New Title** } & $\begin{array}{c}\text { Subject \& Function } \\
\text { Subcategory Codes }\end{array}$ & $\begin{array}{c}\text { Primary Level } \\
\text { of Evidence }^{* *}\end{array}$ \\
\hline 113 & (3) Journal (Water Pollution Control Federation) (1960-1989) & S2.2 & medium \\
114 & (2) Sewage and industrial wastes (1950-1959) & S2.2 & medium \\
115 & (2) Colonial waterbirds (1981-1998) & S3.1 U3.7 U2.10 & high \\
116 & (6) The Wilson journal of ornithology (2006) & U1.2 & low \\
117 & (5) The Wilson bulletin (1894-2004) & U1.2 & high \\
118 & (4) The journal of the Wilson Ornithological Chapter of the Agassiz Association (1893) & & high \\
\hline
\end{tabular}

* Sample is from "JSTOR Currently Available Journals," July 19, 2010.

* Number preceding title shows order of title change, for example "(3)" means this is the third title in the title change history.

$\uparrow \quad$ S1 \& U1 = high-level changes; S2 \& U2 = medium-level changes; S3 \& U3 = low-level changes.

\section{Appendix B. Descriptions of Subject Changes in Sampled Serials}

\begin{tabular}{|c|c|}
\hline $\begin{array}{l}\text { Sample } \\
\text { No. }\end{array}$ & Descriptions of Change by Subcategory* \\
\hline & ADDED A SUBJECT(S) = S2.1 \\
\hline 73 & $\begin{array}{l}\text { S - Began covering commentary on art world activities as they articulate key issues in performance and spectatorship [a major purpose } \\
\text { of journal is commentary] }\end{array}$ \\
\hline 84 & S - Began covering geographical range \\
\hline 15 & S - Began covering numerical analysis and computation \\
\hline 29 & S - Began covering political science \\
\hline 19 & S - Began covering sexual and reproductive health \\
\hline 59 & S - Began covering the cognate sciences \\
\hline 17 & $\begin{array}{l}\text { S - Broadened content from fiction to all genres of literature, along with coverage of ideas and movements in 19th century literature, } \\
\text { and literary criticism }\end{array}$ \\
\hline 1 & S - Broadened content from literature to culture \\
\hline 108 & S - Broadened content from systematic zoology to systematic biology \\
\hline 95 & S - Broadened content to all fields of avian science, within the frame of basic science \\
\hline 53 & S - Broadened subject coverage from folklore to ethnology, to attract other scholars \\
\hline \multirow[t]{2}{*}{65} & S - Broadened the scope of the journal to include the interests of both professionals and non-professionals in the Biblical field \\
\hline & BROADENED CONTENT TO INCLUDE OTHER SUBJECTS = S2.2 \\
\hline 52 & $\begin{array}{l}\mathrm{S} \text { - Broadened content to include art education (providing information, presenting theories and criticisms, announcing opportunities } \\
\text { and resources, and promoting discussion relating to art education) }\end{array}$ \\
\hline
\end{tabular}




\section{Appendix B. Descriptions of Subject Changes in Sampled Serials (cont.)}

\begin{tabular}{|c|c|}
\hline $\begin{array}{c}\text { Sample } \\
\text { No. }\end{array}$ & Descriptions of Change by Subcategory* \\
\hline 98 & S - Broadened the scope to include epidemiology and community health \\
\hline 112 & $\begin{array}{l}\text { S - Expanded coverage to include research on hazardous wastes, groundwater contamination, waste minimization, and environmental } \\
\text { risk and health }\end{array}$ \\
\hline \multirow[t]{2}{*}{91} & S - Expanded scope to include hospital epidemiology \\
\hline & BROADENED CONTENT WITH MORE VARIED COVERAGE = S2.3 \\
\hline 77 & S - Broadened content \\
\hline $104,106,107$ & S - Broadened content by publishing more papers of a shorter length \\
\hline 31 & S - Broadened content to a wider range of articles \\
\hline 71 & S - Broadened content with more varied coverage \\
\hline \multirow[t]{2}{*}{56} & S - Expanded type of style and content that will be accepted \\
\hline & BROADENED GEOGRAPHIC COVERAGE = S1.3 \\
\hline 85 & S - Broadened content by eliminating biogeographical delimitations \\
\hline 2 & S - Broadened content from regional [Midwest] to national [American] aspects of political science \\
\hline 9 & S - Broadened content from regional [Mississippi Valley] to national [American] history \\
\hline 95 & S - Broadened content from regional [Scandinavica] to international \\
\hline 115 & S - Broadened content to include colonial waterbirds anywhere in the world \\
\hline 80 & S - Broadened content to reflect the global connections being made in the field of earth surface processes \\
\hline 40 & S - Broadened content to the world at large, but with the main emphasis still on the Americas \\
\hline 30 & S - Broadened content to wider geographical limits and coverage of issues, though focus remains on the former Soviet block countries \\
\hline \multirow[t]{2}{*}{87} & $\begin{array}{l}\text { S - Changed content from the natural resources of the Chesapeake Bay watershed to any aspect of natural science applied to estuaries, } \\
\text { with no geographical limits }\end{array}$ \\
\hline & BROUGHT TITLE INTO HARMONY WITH CONTENT OF SERIAL = S2.9 \\
\hline 53 & S - Began reflecting the research and scholarship the journal has long embodied \\
\hline 54 & S - Brought the title into harmony with the contents of the magazine [by deleting the word connoisseurs] \\
\hline $63,75,95$ & S - Brought the title into harmony with the journal content \\
\hline
\end{tabular}

BROUGHT TITLE INTO HARMONY WITH STATED SCOPE OF SERIAL = S3.1

\begin{tabular}{ll}
\hline 116 & S - Began reflecting more clearly the journal's theme and content \\
96 & S - Began to more adequately reflect the scope and mission of the journal \\
64 & S - Brought the title into harmony with the aim and contents of the journal \\
77 & S - Brought the title into harmony with the editorial purview of the journal \\
55 & S - Brought the title into harmony with the scope of the journal \\
\hline 59 & CHANGED CONTENT TO REFLECT DEVELOPMENTS IN THE FIELD = S2.4 \\
\hline 92 & S - Broadened content to match the enlarged scope that the term Folklore has reached and the enlarged [non-folklorist] readership that \\
38 & S - Broadened content to reflect a broader integrative view of organismal biology \\
42 & S - Broadened content to the expanding background needed for Biblical studies, and Near Eastern studies in general \\
85 & S - Changed content and emphasis, as the field has matured \\
& S - Changed content to be more in line with the international scientific development in ecology [per requirement of the Nordic \\
57 & Publishing Boards in Science] \\
39 & S - Changed content to movies and TV, as a result of the change that has occurred in Hollywood \\
74 & S - Changed content to resonate with the far-reaching transformations taking place in the Americas
\end{tabular}




\section{Appendix B. Descriptions of Subject Changes in Sampled Serials (cont.)}

\begin{tabular}{lr}
$\begin{array}{c}\text { Sample } \\
\text { No. }\end{array}$ & Descriptions of Change by Subcategory* \\
\hline 103 & S - Changed focus to reflect today's occupational and environmental health problems \\
\hline & CHANGED OVERALL EMPHASIS OR FOCUS = S2.5 \\
\hline 39 & S - Began promoting a reexamination of prevailing social science theory and concepts about Latin America and the Caribbean \\
44 & S - Changed emphasis to applications of statistical thinking to social problems \\
70 & S - Changed emphasis to the ethical dimensions of science and technology \\
\hline
\end{tabular}

CHANGED OVERALL SUBJECT CONTENT $=$ S1.1

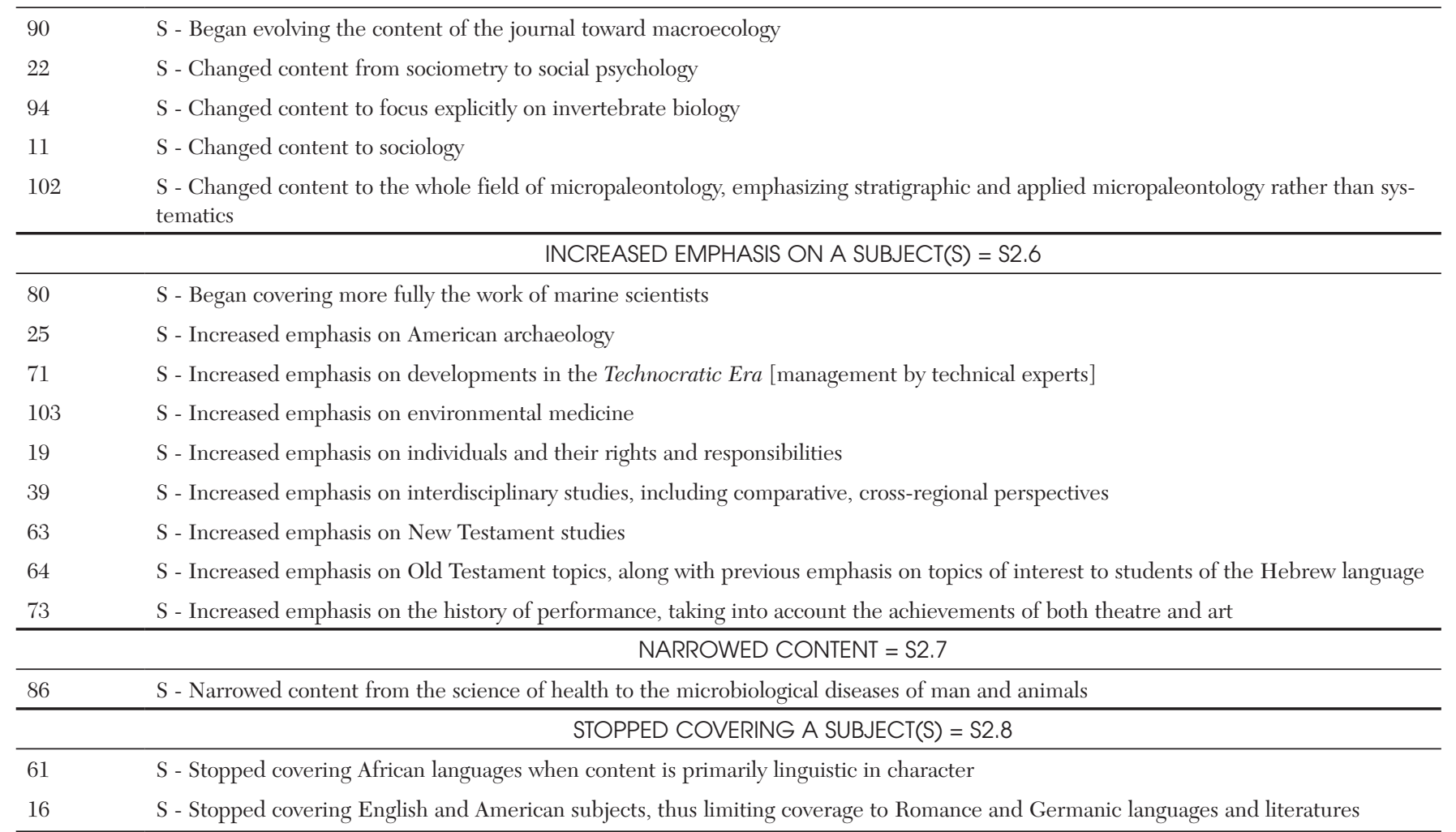

* "S" preceding descriptions stands for "Subject description." Code following subcategory headings is the subcategory code (e.g., S2.1).

\section{Appendix C. Descriptions of Function Changes in Sampled Serials}

\begin{tabular}{|c|c|}
\hline $\begin{array}{c}\text { Sample } \\
\text { No. }\end{array}$ & Descriptions of Change by Subcategory* \\
\hline & ADDED A BIBLIOGRAPHY SECTION = U3.1 \\
\hline \multirow[t]{2}{*}{59} & U - Began including bibliographic information on books and articles, published at home and abroad \\
\hline & ADDED A BOOK REVIEW SECTION = U3.2 \\
\hline
\end{tabular}




\section{Appendix C. Descriptions of Function Changes in Sampled Serials (cont.)}

\begin{tabular}{ll}
$\begin{array}{c}\text { Sample } \\
\text { No. }\end{array}$ & Descriptions of Change by Subcategory* \\
\hline 52 & U - Began including book reviews for undergraduate teaching \\
\hline 39 & ADDED A COMMENTARY, DISCUSSION, OR DEBATE SECTION = U3.3 \\
& $\begin{array}{l}\text { U - Added a Critical Debates section, for publishing provocative review essays surveying major themes in the recent social science litera- } \\
46\end{array}$ \\
95 & U - Added a Discussion section, to include commissioned review articles on Soviet scholarship \\
95 & U - Added a Forum section, for responses to the Point-of-View papers as well as papers on any general issue in avian biology \\
39 & eral themes in avian biology, as well as speculating on future developments \\
89 & U - Added a Policy Issues section, for publishing contributions on contending perspectives on major issues of significant policy relevance \\
91 & U - Began including columns on issues and topics related to hospital epidemiology
\end{tabular}

\begin{tabular}{ll}
\hline & ADDED A CORRESPONDENCE SECTION $=$ U3.4 \\
\hline 72 & U - Added a Answers to Correspondents section \\
57 & U - Added a Correspondence and Controversy column, for expressing views on the articles and events \\
49 & U - Began including correspondence, reports of discussions and symposia, and shorter notes \\
55 & U - Began including letters and rejoinders \\
\hline
\end{tabular}
ADDED A NEWS SECTION = U3.5

\begin{tabular}{l}
\hline $44 \quad \begin{array}{l}\text { U - Added a News Items section, for publishing a) brief summaries of actions by government agencies, professional organizations and the } \\
\text { like, b) reports of teaching programs and research in progress, and c) timely announcements of conferences and fellowship opportunities }\end{array}$ \\
$57 \quad$ U - Began including information from readers on current experimental activities \\
$52 \quad$ U - Began including reports relating to courses and programs, exhibitions, and research projects
\end{tabular}
ADDED A NOTES SECTION = U3.6

\begin{tabular}{ll}
\hline 73 & $\mathrm{U}$ - Added a Art and Performance Notes section \\
57 & $\mathrm{U}$ - Added a Film Quartered department, featuring regular competitions \\
39 & $\mathrm{U}$ - Added a Research Notes section, for publishing shorter pieces dealing with questions of data, theory, and method \\
85 & $\mathrm{U}$ - Added a special section for comments and short scientific notes \\
\hline
\end{tabular}

\begin{tabular}{ll}
\hline & ADDED ABSTRACTS, RESUMES, OR OTHER NEW FEATURES = U3.7 \\
\hline 116 & $\mathrm{U}$ - Added a new feature "Once upon a time" to put forward the observations and reflections of naturalists from times past \\
37 & $\mathrm{U}$ - Began including an abstract at the beginning of each published article \\
42 & $\mathrm{U}$ - Began including new features and departments, intended to expand news coverage, increase dialogue and debate, and generate discussion \\
51 & $\mathrm{U}$ - Began including several additional features, resulting from a series of proposed new directions \\
& $\begin{array}{l}\text { U - Began printing resumes of the Conference proceedings not elsewhere printed, along with references to where the remaining papers } \\
\text { are to be published }\end{array}$
\end{tabular}

\begin{tabular}{ll}
\hline 82 & $\mathrm{U}$ - Began including a State-of-the-Art Clinical Article by an outstanding authority in each issue \\
18 & $\mathrm{U}$ - Began publishing an authoritative article each month on a problem confronting the Institute \\
\hline
\end{tabular}

$18 \mathrm{U}$ - Began publishing an authoritative article each month on a problem confronting the Institute

\begin{tabular}{ll}
\hline 82 & U - Began including an AIDS Commentary in each issue \\
93 & $\mathrm{U}$ - Began publishing commentaries on articles, and invited contributions on topics of interest \\
18 & $\mathrm{U}$ - Began publishing opinion translations on issues between East and West \\
\hline
\end{tabular}

BEGAN INCLUDING CONFERENCE OR SYMPOSIA PAPERS OR PLANS = U2.3

$18 \mathrm{U}$ - Began including presentations of conference problems and plans 


\section{Appendix C. Descriptions of Function Changes in Sampled Serials (cont.)}

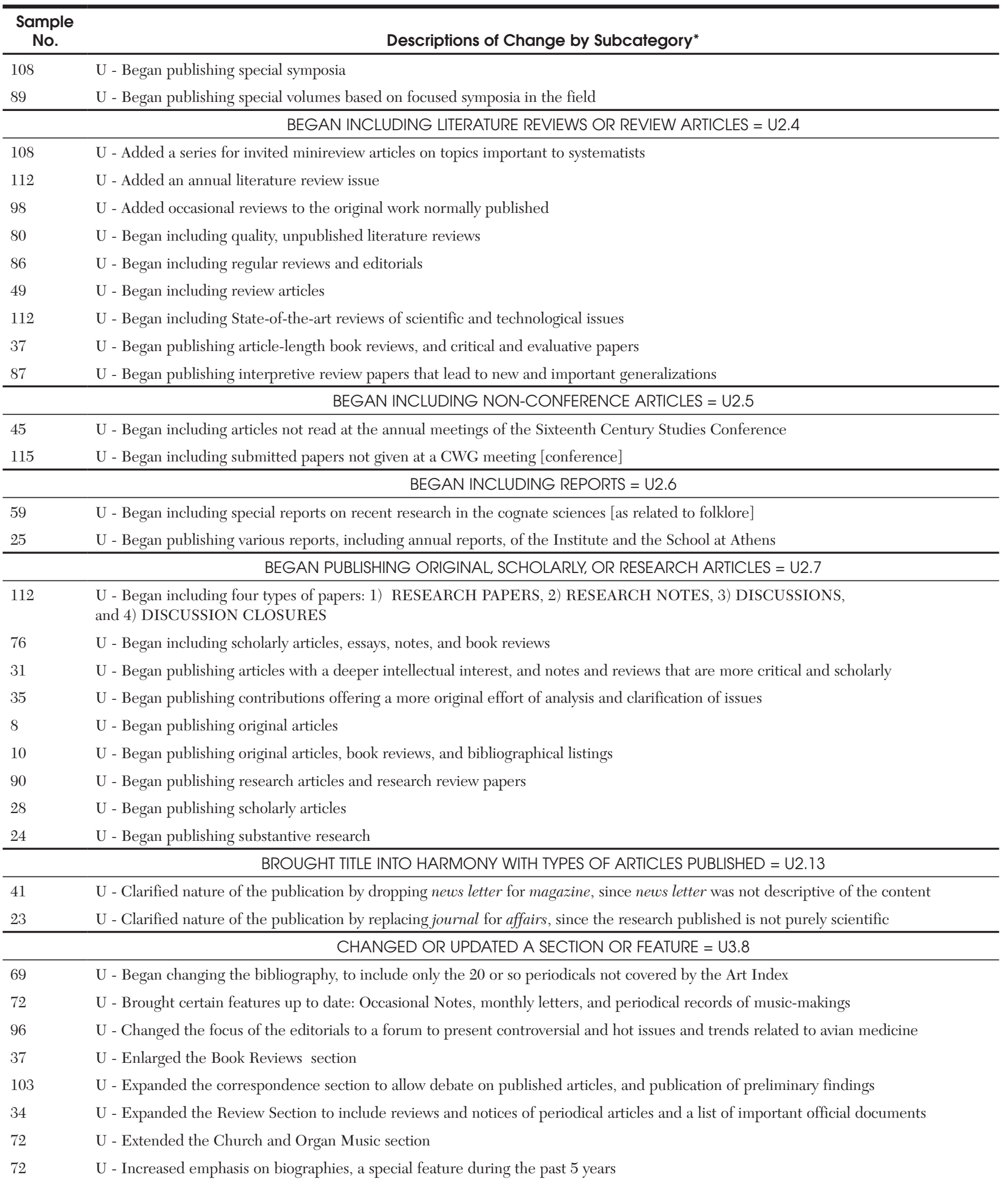




\section{Appendix C. Descriptions of Function Changes in Sampled Serials (cont.)}

\begin{tabular}{|c|c|}
\hline $\begin{array}{l}\text { Sample } \\
\text { No. }\end{array}$ & Descriptions of Change by Subcategory* \\
\hline 42 & U - Regularized and expanded the book review section \\
\hline 37 & CHANGED OVERALL FUNCTION OF SERIAL = U1.1 \\
\hline 26 & U - Began expanding the function of the publication to a journal, by dropping the word bulletin from the title \\
\hline 97 & U - Began reflecting the establishment of the specialty of avian medicine and surgery [in a medical journal] \\
\hline 6 & $\begin{array}{l}\mathrm{U} \text { - Changed emphasis of the publication to providing the means for individual scholars to communicate with one another, through } \\
\text { exchanging and pooling ideas and new knowledge and reviewing past research in relation to current developments }\end{array}$ \\
\hline 14 & $\begin{array}{l}\text { U - Changed focus to serve two major functions of the Institute: 1) to provide sound statistical advice to the public, 2) to keep statisti- } \\
\text { cians up to date with new methods }\end{array}$ \\
\hline 79 & $\begin{array}{l}\mathrm{U} \text { - Changed function from a journal (publishing conference proceedings and short papers) to a yearbook (publishing extensive in depth } \\
\text { studies from original research and surveys of completed or in-progress work) }\end{array}$ \\
\hline 34 & U - Changed function from a journal [suspended due to war] to a supplement [review section of journal] \\
\hline 117 & $\mathrm{U}$ - Changed function from a journal to a bulletin, containing facts reported by members, due to the expense of producing a journal \\
\hline 1 & $\mathrm{U}$ - Changed function from a literature forum to a review \\
\hline 27 & $\mathrm{U}$ - Changed function from a publication with humble beginnings to a scholarly journal \\
\hline 33 & U - Changed function from a supplement [review section of journal] back to a journal [restarted following war] \\
\hline 118 & U - Changed function to a journal \\
\hline 82 & U - Changed to a clinical journal \\
\hline
\end{tabular}

DEVELOPED OR EXPANDED UPON A FUNCTION = U2.8

\begin{tabular}{ll}
\hline 32 & $\mathrm{U}$ - Began developing a more substantial and truly significant journal \\
18 & $\mathrm{U}$ - Began including more comprehensive and valuable materials, but still within the realm of a news bulletin \\
36 & $\mathrm{U}$ - Began publishing longer, more interpretive articles [reports on articles from other sources] \\
103 & $\mathrm{U}$ - Expanded the educational function of the journal to include articles on issues of current importance, as well as methodological papers \\
\hline & INCREASED EMPHASIS ON ORIGINAL, SCIENTIFIC, OR CONCEPTUAL ARTICLES - U2.9 \\
\hline 25 & $\mathrm{U}$ - Began encouraging papers leading to conceptual changes in the subject areas \\
66 & $\mathrm{U}$ - Began publishing more scientific papers \\
& tion - Increased preference for original contributions on treatment and research in all branches of the theory and practice of the conserva- \\
\hline
\end{tabular}
INCREASED EMPHASIS ON THE PEER REVIEW PROCESS $=$ U2.10

\begin{tabular}{ll}
\hline 112 & $\mathrm{U}$ - Began enhancing the rigor of the manuscript review process \\
115 & $\mathrm{U}$ - Changed to a fully refereed journal \\
66 & $\mathrm{U}$ - Increased emphasis on the peer review process by excluding preprint volumes as published volumes of the journal \\
112 & $\mathrm{U}$ - Placed manuscript acceptance decisions under the control of a Board of Editorial Review, to enhance the stature of the Journal in all \\
water quality areas
\end{tabular}
NARROWED THE ARTICLE SELECTION POLICY = U2.11

$68 \quad \mathrm{U}$ - Began limiting the papers published from regular meetings, rather than including all papers STOPPED INCLUDING A FUNCTION = U2.12

$48 \quad$ U - Stopped publishing the content of the Proceedings with the Transactions

* "U" preceding descriptions stands for "Function description." Code following subcategory headings is the subcategory code (e.g., U3.1). 